\title{
A educação escolar indígena no contexto da antropologia brasileira
}

\section{Antonella Maria Imperatriz Tassinarı}

Unıversıdade Federal de Santa Catarma Florianopolıs Brasıl antonella@cfh ufsc br 
Resumo

Este trabalho pretende analisar o hustorıco das polıtıcas educatıvas voltadas para indıgenas no seculo $\mathrm{XX}$ em relação a hustorıa das pesquısas antropologicas na area de etnologia indigena destacando os poucos trabalhos que se dedicai am ao tema da educação indigena em especial a sua educação escolar como a contribuıção pıoneira de Sulvıo Coelho dos Santos São analisados três momentos modelares do seculo XX não por reunirem caracteristicas definidoras de um periodo mas por servirem como divisores de aguas por marcarem rupturas entre momentos anteriores e subsequentes a decada dc $1930 \mathrm{e}$ o modelo do SPI a decada de 1960 e o modelo da FUNAI e a dccada de 1990 e as transformaçoes decorrentes da Constıtuışão Federal de 1988 Tratam se de tres fases importantes no processo de instıtucıonalızação da Antropologia no Brasil e que tambem marcam rupturas nos modelos de politicas educacionais voltadas para indıgenas no Brasıl

Palavras chaves hustorıa da antropologıa etnologıa educação indıgena escola
Abstract

This work analyses the history of Indian educational policyin relation to ethnological research during the twentieth Century Emphasts is placed on the few works dedicated to the theme of Indian education particularly that of formal schooling and also on the pioneer contribution of Silvio Coelho dos Santos Three different moments of the twentieth Century are analyzed not because they link together definttive characteristics of a pertod but because they effectively serve as a divtston of the waters marking ruptures between earlier and later moments the decade of 1930 and the SPI model the decade of 1960 and the model of FUNAI and the decade of 1990 and its transformations resulting from the Federal Constitution of 1988 They are three important phases in the institutionalization of Braztlian Anthropology as well as markers of ruptures in the models of Indian educational policy in Brazll

Key words history of anthropology ethnology Indian education school 
Tnıcıatıvas de educação escolar voltadas para ındígenas ocorreram no Brasıl desde epocas colonıaıs e, de forma sıstematıca, vêm sendo promovidas como politıca pública desde as primeiras decadas do seculo XX, com o objetıvo de nacionalızar esse contıngente da população, atraves do ensino da lingua portuguesa e de permıtır sua assımılação à socıedade brasıleıra A partır de 1970, começa a haver uma mudança de paradıgma a nortear as polıtıcas de educação escolar para ındígenas, culmınando na Constıtuıção de 1988 e nas subsequentes polítıcas de ensıno que reconhecem a dıversıdade cultural dos povos indígenas e visam oferecer condições para a manutenção desse patrımônıo etnıco-cultural

Este trabalho pretende analisar o historico das polítıcas educatıvas voltadas para indígenas no século XX em relação à hıstorıa das pesquısas antropologıcas na área de etnologıa ındígena, destacando os poucos trabalhos que se dedıcaram ao tema, em especıal a sua educação escolar, como a contrıbuıção pıoneıra de Sılvıo Coelho dos Santos ${ }^{1}$

Analıse desenvolvida por Lopes da Silva (2001) revelou uma lacuna entre o desenvolvimento intensivo de pesquisas sobre povos indígenas das ultumas décadas com foco nos temas de parentesco, cosmologia, corporalıdade e ritual, que foı capaz de produzır refınadas analıses sobre as especıfıcıdades socıocosmológıcas das populações estudadas e sıgnificatıvos avanços teorıcos, de um lado, e, de outro, os estudos sobre experiências concretas de educação indígena, os quaıs geralmente discutem questões prátıcas e ımedıatas voltadas a educação bilíngue e ao ensıno diferenciado, mas não incorporam os temas desenvolvidos pelas outras pesquisas Esta lacuna entre os trabalhos teonicos sobre povos indigenas (suas historias, cosmologias rituais, 
organızação socıal) e aqueles sobre escolas indıgenas (suas pratıcas pedagogicas, uso de linguas natıvas) e tambem fruto do sılêncıo da etnologı nacıonal a respeito de questões educatıvas

De fato, esta lacuna não aponta apenas para as duficuldades da operacionalızação do discurso acadêmıco para a solução de problemas concretos em sala de aula Ao consideramos a histona das polítıcas educacıonais voltadas para indıgenas e a historia da etnologıa indıgena no Brasıl, verıfıcamos que as contrıbuıções desta sempre estıveram norteando as politıcas públıcas, mesmo com algumas décadas de atraso Porem, as contribuições da etnologıa indígena versaram sobre tıpologıas das sociedades, culturas e processos hustoricos das populações indígenas, desconsıderando os fenômenos proprıos da educação da transmıssão de saberes, dos processos natıvos de ensmo e aprendızagem

A seguur, analıso três momentos modelares do seculo XX, não por reunirem caracterıstıcas definidoras de um perıodo, mas por servirem como divisores de aguas e por marcarem rupturas entre momentos anteriores e subsequentes Trata-se de fases importantes no processo de instıtucıonalızação da Antropologıa no Brasıl Marcam também rupturas de modelos de politicas educacionais voltadas para indigenas no Brasil

\section{A década de 1930 e o modelo do SPI}

Segundo Souza Lima (1995), no seculo XIX, sob o regime Imperıal no Brasıl, o Munısterıo dos Negocıos do Impérıo legıslava sobre a ocupação das terras e as polıtıcas referentes às populações natıvas, nomeando dıretores geraıs de indıos, duretores de aldeıas e valendose de missionarios capuchinhos para administrar os aldeamentos, tornando-os auto-sustentáveıs através do ensmo de ofícıos aos indíge nas Essas atrıbuıções foram transfeıldas ao Mınısterıo da Agrıcultura Comercıo e Obras Publicas em 1860, e, as vesperas da proclamação da Repúblıca, em 1889, as responsabilıdades sobre os aldeamentos ındígenas foram repassadas diretamente as provincias

Com a Republica e o advento de uma elite cafeeıra paulısta, no sudeste do Brasil, desenvolve se a idela do atraso do mundo rural, de suas técnıcas agrıcolas e de suas populações, que deve ser untegrado a nação atraves do desenvolvimento de tecnicas disciplınares Essa e a proposta 
de atuação do Minısterıo da Agrıcultura, Industria e Comércıo (MAIC) visando estender tecnıcas disciplınares da indústrıa ao meıo rural e suas populações, com uma perspectıva de integra-las num projeto de nação Segundo Souza Lima (op cit), essa forma de construir maginarıamente o mundo rural no Brasıl foı consoante àquela usada para pensar os ind genas como matérıa da ação governamental Com essa perspectıva, fol crıado em 1910, no âmbito do MAIC, o Serviço de Proteção aos Índıos e Localızação de Trabalhadores Nacionais (SPILTN)

Crıado pelo mulıtar Cândıdo Marıano da Sılva Rondon, o SPILTN baseava se no idearıo positıvista leıgo, implicando num afastamento entre politıca undigenısta e ação catequetıca Consıderando os indigenas como "brasıleiros pretérıtos", as ações do SPILTN visavam "proteger" essas populações em sua sıtuação transitóıla rumo à sua incorporação à sociedade nacional Como demonstra Souza Lima (op cit), as polıtıcas que produzıam uma certa forma de 'indıanıdade' eram tambem aquelas que criavam uma ideia de "sociedade nacional "

Sob a marca da "tutela", as políticas indigenistas no Brasıl foram desenvolvidas pelo SPITLN, que passou a ser denomınado apenas Serviço de Proteção ao Índıo (SPI) a partır de 1918, e, em 1930, delxou de integrar o Mınıstérıo da Agricultura, Industrıa e Comercıo para fazer parte do Minıstérıo do Trabalho, Industria e Comercio O orgão fol extınto em 1967, quando foı crıada a Fundação Nacıonal do Indıo (FUNAI)

As populações indıgenas eram então classıficadas como "mansas (ou alıadas) e "bravas (hostıs) A proposta do SPILTN era estabelecer alıanças com os índıos "mansos" e levar a paz aos "bravos", a partır da estratégıa de produzır "um grande cerco de paz" Segundo Souza Lıma, trata-se de tecnıca mulıtar de pressıonar uma população hostıl a aceitar uma alıança que se lhes apresenta como unıca alternatıva Se, por um lado o cerco de paz" cria uma zona de proteção aos inımigos externos (as pressões da sociedade envolvente), tambem corta a liberdade de circulação, estabelece vigılâncıa e controle

As ações do SPILTN varıavam conforme a situação de contato e alıança com a população indıgena A prımeira fase de ação frente aos índıos consıderados arredıos ou hostıs era denomınada "pacıfıcação' Através da doação de bens, agentes do SPITLN procuravam estabelecer 
os prımeuros contatos e "atrair" populações para um territorıo delımıtado, as "reservas undígenas", visando inıciar um processo de seden tarızação A segunda fase ela proprımente a da "educação", através da implantação de escolas e da fuxação dos indigenas num terrıtóno admınıstrado por um posto indígena A terceira fase desenvolvıa ações para a "cıvilızação" dos indıgenas preparando-os para serem "trabalhadores nacionaıs' Além da educação escolar visando o ensino da lıngua portuguesa, e noções de matemátıca para o comércıo, tambem eram transmitıdas técnicas agricolas, pecuarıas e industriaıs Uma quarta e últıma fase previa a emancıpação defınıtıva dos ındıgenas e sua introdução na "vıda cıvılızada", segundo o ıdeárıo posıtıvısta

Percebe-se que a educação escolar era importante estrategıa para a "cıvılızação" dos indıos no interıor de uma polítıca de integração da nação Isso fol especialmente marcante em regıões de fronterras, em que a escola cumpriu papel de incentivar um idearıo nacionalısta brasıleıro nos ındígenas, coıbındo manıfestaçóes culturaıs que os aproximavam dos paises vizınhos Em trabalho anterıor (Tassinarl 2001a), descrevo esse processo entre os índıos do vale do rıo Uaça, na reglão de fronteura com a Guiana Francesa Sobre a mesma regıão, a dıssertação de Assıs (1981) - a prımeira a tratar do tema da educação escolar - define as escolas indigenas como frentes ideologıcas"

A década de 1930 pode ser considerada como sendo um divisor de aguas nesse processo de ruptura de uma politıca indigenista descentralızada e ancorada na ação catequetıca do seculo XIX, para uma polıtıca vısando à ıntegração nacıonal, laıca e milıtarızada O contexto polıtıco do Estado Novo (sob a presıdência de Getulıo Vargas, de 1937 a 1945) consolıda esse movimento através da "marcha para o Oeste", visando a ocupação e integração do terrıtorıo nacional

E o que ocorrıa no campo da Antropologıa brasuleıra nesse mesmo perıodo? Ao analısar a produção da Antropologı no Brasıl Melattı (1984) aponta os anos 1930 como um marco na instıtucıonahıação dessa área do conhecimento, antes pratıcada por engenheuros, médicos, militares, joinalıstas, dentre varıos autores que se dedicaram a registiar o modo de vida de indıos, negros e sertanejos Segundo Melattı, os trabalhos de etnologia indigena realizados no seculo XIX 
até a década de 1930 revelavam um descompasso entre certa sımpatıa dos autores pelas populações estudadas e as ıdeıas racıstas da epoca, que as colocavam em situação de inferıorıdade, como o indıanısta Antonıo Gonçalves Dıas, o milıtar José Vıeıra de Couto Magalhães e o engenheiro Antonı Manuel Gonçalves Tocantıns, dentre outros

As ıdeıas racistas e evolucıonıstas que mobilızaram essas prımeıras investıgações etnologicas desenvolvıdas antes da década de 1930 estavam mutas vezes subjacentes ao ideario positivista das politicas publicas acima descritas No entanto o grande debate do inicio do século XX a respeito das populações ındıgenas ocorrıa entre os par tıdarıos de Herman von Iherıng, que defendıa o exterminı destas, consıderadas empecilho ao progresso e à cıvilızação, e as ıdeıas de Rondon, calcadas em ideaıs humanitárıs, defensor de uma integração progressiva e pacifica $\mathrm{E}$ no âmbito desse debate que etnologos, como Curt Nimuendaju, tomaram o partıdo de Rondon e colaboraram com os trabalhos do SPI (Gonçalves 1993)

A decada de 1930 marca o momento de instıtucıonalızação da Antropologia no Brasıl, com a crıação de faculdades para a formação de profissıonaıs da área Em 1934 foı crıada a prımeira Faculdade de Fılosofıa, Ciências e Letras no Brasıl, na Unıversıdade de São Paulo, onde lecionaram Roger Bastıde, Emılıo Willems e Lévi-Strauss Também nessa epoca, na mesma cidade, e fundada a Escola de Sociologia e Politica (ESP), na qual lecıonaram Herbert Baldus, Donald Pıerson e RadclıffeBrown, fazendo de São Paulo o prıncıpal foco de uradıação da Etnologıa no perıodo Em 1935 fol criada a Unıversidade do Distrıto Federal no Rio de Janeiro, onde lecionaram Gilberto Freyre e Arthur Ramos

Desde então, as pesquisas em etnologıa voltam-se para estudos mais sıstematıcos e intensıvos sobre as populações estudadas perdendo o interesse nas explıcações evolucıonıstas Melattı (op cıt) destaca, nesse período, a contribuição de pesquisadores alemães, como Herbert Baldus e Curt Nimuendaju, ou de orıgem alemã, como Egon Schaden e de pesquisadores franceses, como Levi-Strauss e Afred Metraux N1 muendaju produzıu obras extensas sobre os povos Guaranı, Xerente, Canela, Apınaje e Tukuna, e realızou descrições de língua mitologia, organızação socıal e hıstorıa de várıas populações ındígenas Essa pro- 
dução etnológica, portanto, estava em dialogo com a tradıção alemã (que naquele perıodo era desenvolvida por Franz Boas e colaboradores nos Estados Unıdos) e com o campo dos americanıstas franceses

Doıs autores voltaram sua atenção para a educação ındıgena no Brasıl, com artıgos que poderíamos chamar de "inauguraıs" sobre o tema Willems (1938) e Schaden (1945) O artıgo de Willems baseıase em pressupostos evolucionistas e compara "povos civilizados" e "povos de cultura pobre", "culturas superiores" $\mathrm{e}$ "povos periférıcos' ou "povos naturaıs" Com tais premissas, não e de se estranhar que chegue a conclusões de que "não ha um sistema educatıvo objetıvo entre os chamados povos prumitıvos, existe apenas educação como transmıssão Não há pedagogıa" (Willems 1938 6) Aında assım vêm de Willems as primeiras crítıcas às escolas em aldeıas indıgenas Segundo o autor, "a escola não dız respeito à vıda natıva e não permite a inserção na vida colonıl" ( $\imath$ d $\imath$ b 34) Ela faz com que os alunos passem a desprezar a vida e os conhecimentos de seus antepassados sem, contudo, consegur espaço fora da aldeıa O trabalho de Schaden já se utılıza de conceitos funcionalıstas e parte do pressuposto de que há outras formas de educação além daquela sıstematıca e baseada na escrita que caracterıza a educação escolar Schaden anahisa como a "função educatıva", isto é, a "constante preocupação de se transmitır às novas gerações o patrumônıo cultural elaborado durante longo perıodo de vıda comunitarıa", pode ser realızada nas sociedades indigenas pelas cerımônıas de ınıcıação

Melattı (op ctt) tambem destaca que a decada de 1930 for momento de produção das prumeiras interpretações gerais do Brasıl, como as obras de Gilberto Freyre e de Sergio Buarque de Holanda Como mencıonado acıma, essas interpretações do Brasıl, ao criarem uma ıdeıa de "sociedade nacional" tambem estabeleciam nela um lugar para as populações ındıgenas, notadamente um lugar pretérıto de "matrız" de uma cıvilızação que virıa substıtuí-las

Se observarmos as polítıcas publicas voltadas para indígenas no Brasil veremos que as escolas em funcionamento nas aldeıas, sob tutela do SPI, pautavam-se em ideias positıvistas e evolucionistas (especialmente o projeto de "civllıação dos selvagens"), presentes 
na produção etnológıca do período anterıor Ao mesmo tempo, o projeto de "Integração nacional" através da educação escolar estava em consonância com contribuıções da Antropologıa que se desenvolvia a partır da década de 1930

\section{A década de 1960 e o modelo da FUNAI}

No campo da etnologıa indigena, as decadas que se segurram ao perıodo de instıtucıonalızação acadêmıca viram crescer os estudos sobre mudança cultural ou "aculturação', desenvolvidos por Herbert Baldus Egon Schaden, Charles Wagley, Eduardo Galvão, entıe outros Segundo Melattı (op cıt ), no final dos anos 50 Darcy Rubeiro e Roberto Cardoso de Olıveıra começam a repensar as abordagens clássıcas de aculturação, inserundo algumas varıantes atentas ao carater das "frentes de expansão" ou de "transfigurações etnıcas' O autor tambem aponta nesse perıodo, a influêncıa da abordagem funcıonalısta nos estudos sobre populações indigenas

Esse é o enfoque do trabalho de Florestan Fernandes (1966) sobre a educação entre os Tupınambá Apesar de se basear em relatos de cromıstas, pode ser consıderado o primeiro trabalho mais sıstematıco sobre educação indıgena no Brasıl Qualıficando a sociedade tupınambá como "tradicionalista, sagrada e fechada", o autor descreve os cuidados com as crıanças, as classıficações das fauxas etarıas femınınas e masculınas e suas posıções de status, e aponta algumas característıcas do processo educatıvo, com ênfase no "valor da tradıção da ação e do ex€mplo' Identıfica certas esferas de transmissão de conhecımentos especificos, como as "escolas matrimoniass' (como denomina a aprendizagem de técnıcas sexuals), ou a aprendızagem dos conhecımentos dos pajes Aında assım, prefere qualıficar a educação tupınambá como "ensino informal e não sistematizado"

A atuação de alguns pesquısadores junto ao SPI, até final da déca da de 1950, contribuiu para a formação de uma geração de undıgenıstas com solıda formação etnologıca Melattı (op ctt) menciona os "Cursos de Aperfeıçoamento/Especıalızação em Antropologıa Cultural' , ınıcıados em 1955, no Museu do Indıo, orgão lıgado ao SPI, e coordenados por Darcy Ribeiro ${ }^{2}$ Esses cursos foram tambem importantes para a formação de uma geração de antropologos que ıra consolıdar a pós- 
graduação em Antropologıa nas décadas seguintes em várıos centros brasıleiros, tendo o Rio de Janeiro como foco irradiador Segundo Melattı (2002 181) "Tudo começou com os cursos de especialızação em Antropologıa Cultural munistrados por Darcy Rıbeiro na segunda metade dos anos 50, dois deles no Museu do Indıo Inspirado nesses cursos, Roberto Cardoso de Olıveira, que deles havia partıcıpado como professor auxilıar, organızou no Museu Nacional o primeiro 'Curso de Teoria e Pesquisa em Antropologia Social', em 1960

Esses cursos de especialızação oferecıdos na então Unıversıdade do Brasıl no Museu Nacional, coordenados por Roberto Cardoso de Olıveıra, são lembrados por seus alunos como experıências marcantes e definidoras de um ethos profissional que fizeram perpetuar em suas carreiras E o caso de Silvio Coelho dos Santos, ingresso na turma de 1962, formado no ano seguinte Santos prossegue os estudos realizando doutorado na USP e atua na Unıveı sıdade Federal de Santa Catarına, em sua cidade natal, onde lıdera a instıtucıonalızação de um Programa de Pos-Graduação, na decada seguinte

Para Correa (1995), a decada de 1960 pode ser considerada um marco na instıtucıonalızação da Antropologıa no Brasıl segundo novos moldes que passam a nortear a criação de cursos de pos-graduação Se até o inícıo dessa década a formação em pos-graduação de Antropologıa só era oferecıda pela Unıversıdade de São Paulo, cınco novos cursos são fundados ate o funal da década segumte Em 1968 for criado o Programa de Pos-Graduação em Antropologıa Socıal do Museu Nacıonal, no Rıo de Janeıro, seguindo a nova legıslação Em 1970, a pós-graduação da Unuversıdade de São Paulo fol remodelada para se adequar às novas exıgências da Reforma Unıversitárıa Em 1971 fol crıado o mestrado na Universidade Estadual de Campinas, em 1972, na Unıversidade de Brasılıa, em 1977 na Unıversıdade Federal de Pernambuco, e, em 1979, na Unıversıdade do Rıo Grande do Sul

Em outros centros, a formação em Antropologıa passa a ser oferecida como Especialızação', como na Unıversıdade Federal do Paraná, em 1972 e na Unıversıdade de Santa Catarına, em 1976 transformando-se em "area de concentração" do mestrado em Clênclas Socıaıs em 1978 Tiata-se de um processo que institucionalıza dentro 
A educaçao escolar indıgena no contexto da antropologıa brasıleıra

de uma nova confıguração a produção e o ensino de Antropologıa, que já vinham sendo realızados nesses centros, algumas vezes no âmbito de museus ou institutos universitarios, conforme descreve Santos (2006) em relação ao sul do Brasıl

Além das mudanças no âmbito da organızação das unıversıdades brasıleıras, há também sıgnıfıcatıvas modıfıcações nas orıentações teoricas da etnologia, tambem a partır dos anos 1960 Segundo Melattı (op cit) 'os estudos de contato interetnico, antes voltados para as modıficaçóes culturaıs, atentam agora maıs para o conflito entre unteresses, regras e valores das sociedades em confronto Preocupações de carater estruturalısta e etno-cıentıfico substıtuem as interpretações funcionalistas" (p 153)

Começam a ser desenvolvidos projetos de equipe visando análıses comparatıvas sobre situações de contato interétnico ("Estudos Comparatıvos de Sociedades Indígenas no Brasıl" e "Projeto Areas de Frıcção Interetnıca", coordenados por Roberto Cardoso de Olıveıra, no Museu Nacional), e sobre estrutura social centrado nos povos de fala Jê (Pıojeto Harvaıd/Museu Nacional, coordenado por Davıd Maybury-Lewis e Roberto Cardoso de Olıverra), conforme Melattı (2002) A intensıfıcação das pesquısas de campo, a dıversıfıcação das áreas pesquisadas (além dos grupos de fala jê do Brasıl Central, as atenções sobre o alto Xıngu, o alto rıo Negro e Roraıma) e o dıalogo com as contribuições recentes de antropólogos norte-americanos, ingleses e franceses (especialmente a influêncıa de Claude Levı-Strauss) produzem um corpo de dados substanciais sobre os povos indigenas brasıleıros que e a base de importantes mudanças ocorridas na etnologıa indígena sul-americana no final da década de 1970

As conclusões dos debates ocorridos no Congresso dos Americanistas, em Parıs, em 1976, e no Rio de Janeiro, em 1978, sugerem a importância de compreender essas sociedades em seus próprios termos, afastando-se daqueles construídos para as sociedades africanas (linhagens, segmentos, reinos) e apontando para o rendimento das categorıas "tempo, espaço, pessoa e corporalıdade" Com esse enfoque, destacam-se dois trabalhos pıoneıros sobre educação indigena $\mathrm{Me}$ traux \& Dreyfus Roche (1958) e Melattı \& Melattı (1979) Este sobre 
os Marubo, e, aquele, sobre os Kayapó, do Xıngu, são os prımeiros a focalızar propriamente a crıança indígena no Brasıl Ambos descrevem os cuidados corporals dedicados a gestante e ao recem nascido, as categorias natıvas de "infâncıa", algumas vivêncıas infantıs e as atıtudes educativas dos adultos

E o que ocorria nesse penodo com as polıticas educacıonaıs voltadas para indıgenas? Arnaud (1989), ao analısar a ação indıgenısta em vánas regıões do Brasıl, demonstra que, de fato, ao longo dos anos 1940 e 1950, a politıca desenvolvida pelo SPI produzıu uma nova configuração de aldeamentos indígenas em torno de postos de atração, postos de vigılâncıa e dos postos indıgenas, contribuindo para uma sıtuação de dependêncıa destas populações em relação ao orgão de proteção Enquanto a educação escolar fol estratégıca no processo de pacıfıcação, cıvilızação e nacıonalızação dessas populações, a escola deıxa de ser um investumento prioritarıo na medida em que se tornaram sedentarıas e dependentes da ação governamental Ao longo dos anos 1950 e 1960, varıas escolas e postos estabelecıdos deıxam de receber atenção e financlamento, enquanto o SPI se volta para atender as demandas dos conflitos e novas frentes de atração no sul do Pará

Em todo o pars, começam a haver denuncias de abusos de chefes de postos na exploração do trabalho de indígenas e no estabelecumento de alıanças com politıcos locais, como alternatıvas para obter alguma autonomia financeira E nesse contexto que o SPI $\epsilon$ extmto em 1967, e a polıtıca ındıgenısta do Estado Brasıleıro passa a ser realızada pela Fundação Nacıonal do Índıo (FUNAI)

A atuação de Darcy Rıbeiro e de seus alunos na reformulação e expansão da pos-graduação em Antropologıa no Brasıl é tambem fundamental para a formação de profıssıonaıs indıgenıstas, com os cursos oferecıdos no Museu do Índıo De fato a teorıa de Darcy Rıbeiro sobre o processo de transfıguração etnıca e sua classıfıcação das etapas da integração são importantes fundamentos da atuação da FUNAI

Ribeiro (1970) defende que "no processo inexoravel de integração dos ındıgenas a socıedade nacıonal" (aunda defınıda como cıvilızação"), algumas etapas são identıfıcáveıs A prımeira é a dos índıos "isolados", que vivem em zonas não alcançadas pela socıedade 
brasıleura e so experimentaram contatos raros e acidentais com 'civilızados" A segunda e a dos grupos que mantém "contatos intermitentes com a cıvılızação vivendo em regıões que começam a ser ocupadas por frentes de expansão, mas que ainda mantem certa autonomia cultural e econômica A terceira etapa e a do "contato permanente", vivıda por populações indígenas em comunıcação dureta e permanente com segmentos variados e numerosos da sociedade nacional, ja depen dentes de artıgos industrializados e inseridos na economia mercantıl da regıão, embora mantendo certos costumes tradicionais A quarta e últıma etapa e dos grupos "integrados , confınados em parcelas unflmas de seus antıgos territorıos, já totalmente inserıdos e dependentes da economia regıonal, falantes do português, mestıçados, mantendo apenas como distınção sua "lealdade étnıca" Segundo o autor, "aparentemente haviam percorrıdo todo o caminho da aculturação mas para se assimularem faltava alguma colsa imponderavel - um passo apenas que não podiam dar' (p 262)

Com essa perspectıva fundamentando as ações da FUNAI, a educação escolar promovida pelo orgão foı caracterızada por uma sérıe de ambıguıdades, marcadas por contınuıdades e ruptuı as com o modelo do SPI Havia contınuıdade com o objetıvo de utılızar a educação como estrategıa auxılıar para o processo de assımılação dos ındıgenas a so cledade brasıleura Porem, havıa uma dıferença em relação a atıtude da escola frente as linguas natıvas Enquanto as escolas do SPI utılızavam apenas a língua portuguesa, desestumulando ou proıbindo o uso de linguas natıvas, a polıtıca educacıonal desenvolvida a partır dos anos 1960 reconhecia a importância do uso da lingua materna para a alfabetızação e a ıncorporava nas sénies inıcıaıs, como etapa intermedıarıa de um processo que tambem deverı levar a assımılação

A necessıdade de utılızar as lınguas maternas nas prımeıras sérıes escolares levou a FUNAI a estabelecer um convênı com Instıtuto Lın guıstıco de Verão (SIL), em 1969 Organızação protestante, o Summer Institute of Lingutstıcs, fundado no México em 1935, congrega linguistas preparados para grafar lınguas indigenas com o intuito de realızar proselıtısmo relıgıoso e traduzır a Bıblıa em várıos ıdıomas Segundo Mindlın (2004), a FUNAI reatou convênıo com o SIL ainda em 1983.

\section{ILHA}


dando-lhe a incumbência educacional junto a 53 povos Somente em 1999, o parecer do MEC sobre o SIL reforça a necessidade do ensmo laıco nas aldeıas indigenas

Essa integração progressıva das linguas natıvas no processo escolar e a contratação de indıgenas como professores auxilıares (chamados monitores bılıngues) foı o inıcıo de uma mobılızação indıgena que levou ao desenvolvımento do projeto da educação escolar dıferenciada, bulíngue e intercultural, visando a autodeterminação a valorızação das línguas e culturas indígenas e a manutenção de suas dıferenças étnıcas

Este momento da educação escolar indıgena no Brasıl é analısado pelo trabalho pıoneiro de Silvio Coelho dos Santos, Educação e Socıe dades Tribais, de 1975 Com o objetivo de "esclarecer as possibilidades e lımites da educação formal para que os indígenas do sul do País encontrem melhores condıções de vida, consıderada sua sıtuação de convívio com componentes da sociedade nacional (op cit 9), o autor pesquisou 28 escolas situadas nos 19 postos indigenas da região sul do Brasil, configurando o primeiro projeto de pesquisa sistemátıca sobre o tema Santos fornece um quadro vivo das escolas e seus impasses, ao descrever os espaços físıcos das escolas, a formação e a motıvação dos professores não ındıos que nelas atuavam, as dıfıculdades de dıálogo destes com as crianças, e as expectatıvas dos índıos Com ısso, demonstra como seu funcionamento contrıbuı para a reprodução de preconceitos e estereotıpos de inferıorıdade dos indıos e de uma situação de subordunação dos indígenas no quadro econômuco e polítıco regional Ou seja, se as escolas não cumprem mınımamente sua função educatıva, ao levar constantemente as crıanças ındıgenas ao fracasso escolar, acabam cumprindo outra função "a de convencer os untegrantes das camadas dommantes da sociedade envolvente de que os indígenas estão sendo adequadamente cuidados e que se mais não aproveitam e porque não querem ou são incapazes" ( $l d l b 55$ )

Sílvıo Coelho dos Santos também analısa a prımeira experıêncıa sıstemátıca de ensıno bılíngue para indıgenas, ıdealızada pela mıssıonárıa Ursula Wiesemann para os Kanngang Mesmo ressaltando o mérıto dessa unıcıatıva, o autor destaca alguns desafios aunda presentes, como o questıonamento das consequências do letramento de popu- 
lações não ágrafas e da crıação de um segmento "assalarıado" dentro da aldeı, geralmente ocupado por famılıas de prestıgıo

É importante ressaltar que essa obra, como outras do autor (Indios e Brancos no Sul do Brasil, de 1973, por exemplo), e acompa nhada de um "plano de ação", no qual são apresentadas propostas concretas para uma polıtıca ındıgena à luz das conclusões obtıdas com as pesquisas No caso da educação escolar, Santos consıdera que “ımagınar a utılızação da educação formal como solução para conduzır uma sociedade a melhor es condıçóes de vida socıoeconômıca e ıngênuo ( ) Ha que utılızar a educação como parte integrante das ações promovıdas pelo indıgenısmo ofıcıal, cujos objetıvos merecem ser melhor defunıdos e eleitos perante as condıções apresentadas pelas populações a que pretende servir" (id lb 7l) É nesse sentıdo que o autor propõe um programa de "educação peımanente", que só poderıa ser realızado a partır de uma reformulação global das politicas indigenıstas, mas que infelızmente nunca foi desenvolvido “uma programação que denominamos de educação permanente, voltada para dotar os indígenas dos instrumentos necessarios para partıcıpar da escolha das soluções dos problemas decorrentes de seu convívio com a sociedade nacional, tornando-os conscientes do processo hıstórıco que estão a viver e habılıtando-os para decıdır sobre seu destıno, ( ) promovida por todos os elementos 'civilizados em tıabalho nos postos e voltada para oferecer aos indígenas ensınamen tos e informações destınadas à sua utılızação pratıca em forma de respostas aos problemas do cotıdıano" O programa tambem abarcarıa os indios residentes fora das aldeıas, contribuindo para disseminar novas condıções de relacıonamento com não índıos e promovendo o desaparecımento de estereótıpos sobre as populações ındıgenas

Em resumo, verıfica se, também nesse período, a contribuıção da etnologıa ındıgena na construção de tıpologıas usadas pelo Estado para classıfıcar as populações ındígenas e defınır suas estrategıas de atuação Há tambem um investımento da formação de quadros indıgenistas para o Estado Por outro lado, as critıcas às ações do Estado passam a fazer parte da produção etnologica bıasıleura 


\section{A década de 1990 e as transformações decorrentes da Constıtuução de 1988}

No campo das politıcas publicas, o sistema de ensino brasıleiro passou por uma ampla reformulação a partır da promulgação da Constıtuıção Federal, em 1998, seguıda pela aprovação da nova Lex de Diretrızes e Bases da Educação Nacıonal em 1996 A educação escolar voltada para os povos indıgenas passou progressıvamente a ter prerrogatıvas diferenciadas do sistema de ensino nacıonal Pela primeira vez na hıstórıa do País a Constıtuıção reconhece a dıversıdade cultural e estabelece direıtos diferenciados aos povos indigenas ${ }^{3}$ Dentre estes, o direıto a uma educação escolar que utılıze suas línguas maternas e processos proprios de aprendızagem ${ }^{4}$ Estes dispositıvos constıtucıonaıs são consoantes com aqueles expressos na Convenção 169 da OIT (embora a Constıtuıção tenha sıdo promulgada um ano antes da Convenção, esta so fol ratıficada pelo Brasıl em 2002)

É precıso consıderar que a Constıtuıção foı elaborada e aprovada num contexto de redemocratızação do País Lideranças indígenas de dıferentes povos, com o apoı de intelectuais e relıgıosos, ao longo dos anos 1980, atuaram junto à Assembleıa Constıtuınte, reıvındıcando o reconhecimento de dureitos que assegurassem sua continuidade como grupos etnıcos dıferencıados Desta mobılızação partıcıpou atıvamente Sílvio Coelho dos Santos, que analısou seus resultados na obra Os Indigenas e a Constitutnte de 1989

Podemos consıderar a decada de 1990 como um divısor de águas na historıa da educação escolar ındigena no país, embora autores como Ferreira (2001) e Lopes da Silva (2001) apontem a decada de 1980 como esse divısor de aguas, consıderando as mudanças em curso desde os anos 1970, promovidas pelo movimento indıgena e em virtude do marco da data da promulgação da Constıtuıção Porém, consıdero que é somente a partır de 1990 que os principıos constıtucıonaıs têm desdobramentos concretos Nesse cenárıo legal e de projeto de Estado, as escolas indigenas contemporâneas foram definıdas como ' diferenciadas" "bılíngues" e "interculturaıs" Cada comunidade indigena tem garantıda a liberdade de definir seus projetos pedagógicos e curriculares que, no entanto, têm que ser 
A educaçao escolar mdıgena no contexto da antropologıa brasıleira

reconhecıdos pelo Mınıstérıo da Educação de modo a garantır aos alunos egressos a continuidade de seus estudos

Em 2005, o censo escolar registrou 2323 escolas indígenas, com 163693 alunos matriculados, e 8431 professores $^{5}$ Vale ressaltar que a quase totalıdade destas escolas funciona em aldeias indígenas, sendo que apenas 1,6\% localıza-se em areas urbanas Apesar da legıslação, somente 1818 escolas declararam utılızar linguas indıgenas e 965 declararam possuir material dıdátıco especıfico ao grupo etnico Em 2007, o censo voltado para escolas indígenas regıstrou 2422 escolas indigenas com 174255 estudantes matriculados

Consultado pela Comıssão de Educação da Assembleıa Legıslatıva para a elaboração do proxımo Plano Nacıonal de Educação, Sílvıo Coelho dos Santos e colaboradores apontaram o seguinte diagnostıco sobre a situação da educação escolar indıgena no Brasıl (Santos et allı 2007)

No que se refere a educação conforme explucitado na Leı de Duretrizes e Bases da Educação Nacional (1996) os povos indıgenas tıveram assegurados o dureıto a uma educação diferenciada centrada no ensıno bilıngue no respeıto as suas tradıções culturais e no dureıto de oportunıdades

A educação indıgena passou para o âmbito do Mınısterıo da Educação tendo como potenciais intervenientes os Estados e os Municipios A formação de professores indigenas fol estımulada de sorte que hoje ha um expressivo numero de docentes com formação superior $\mathrm{O}$ ensino fundamental porem não atende a todas as areas reservadas sob a admınıstração da Fundação Nacional do Indıo Em alguns casos parte da população indigena e atendıda por escolas de segundo grau

A população indigena do pais e formada por 220 povos indigenas que professam 180 linguas $O$ pais portanto, e multı societarıo e plurietnico A população que vive em Terras Indıgenas soma a 480000 pessoas Fora das TIs vivendo em areas rurais ou urbanas existem no minımo 250000 indigenas, resultando numa população aproximada de 730000 pessoas O censo escolar INEP/MEC registrou em 20072422 escolas indigenas (fundamental incompleta completa e de ensino medro) A matricula em 2007 atingiu a 174255 estudantes O Fundeb (MEC) passou a suprir com recursos financeiros as escolas indigenas

No que tange as escolas undigenas houve um megavel investımento governamental para colocar em pratıca as exıgências da legıslação No Minısterıo da Educação e nas Secretarıas Estaduaıs de Educação foram criados departamentos voltados para o desenvolvimento de politicas educacionais para indigenas Foram elaborados parâmetros curriculares para as escolas indıgenas e para a formação de professores undıgenas 
Foram desenvolvidos programas de formação de professores indıgenas para atuar nas escolas Foram publicados livros didaticos em linguas nativas A respeito do ensino sobre indigenas nas escolas regulares muito pouco fol realizado no sentido de proporcionar o reconhecimento e a valorızação da sociodıversıdade e principalmente, dos saberes indıgenas Analıses dos livros didatıcos utılizados em escolas publicas no Brasil revelam que aunda são veıculadas informações preconceıtuosas sobre as populações indıgenas

Aında no mesmo documento, as seguuntes diretruzes são propostas para para as polıtıcas de educação escolar ındıgena no Brasıl (Santos et all 2007)

Os avanços na area de educação indıgena pos Constıtucção de 1988 foram sıgnıfıcatıvas $O$ fato de o Munısterıo da Educação ter substıtuido a Fundação Nacional do Indıo (FUNAI) na manutenção e patrocınıo das escolas indigenas significou importante diferencial Contudo, ha de se considerar que os avanços não foram unuformes, de tal sorte ha grupos anda desassıstıdos outros que não têm interesse na educação formal e aunda, poucos que não estão sendo assıstıdos por falta de contato com a sociedade nacional

A criação da categorıa escola undıgena (conforme Resolução CEB03/1999 e Plano Nacional de Educação/2001) contrıbuıu para a efetıva consolıdação das experiências de educação diferenciada em andamento e permitıu o reconhecimento das escolas das aldeıas mas o processo aunda esta em curso e necessita atingir a totalıdade das escolas indigenas $\mathrm{Ha}$ que se considerar tambem que com a crescente presença de indigenas em centros urbanos ha a emergência de demandas de escolas undigenas com regimentos e curriculos diferenciados fora das aldeıas

Quanto aos avanços deve se ressaltar a formação de professores indıos em cursos de nivel medio ou superior Outrossim a preparação de material didatico especifico muto contribuiu para o desenvolvimento escolar dos alunos indios Estudos tambem foram realızados em diversas linguas indigenas facilıtando o seu registro e processos de alfabetızação

O aspecto mais inovador da legislação e o reconhecimento de que os indıgenas não so possuem sua organızação social costumes lınguas crenças e tradıções mas princıpalmente que utılızam processos proprios de aprendızagem que precisam ser levados em conta pela escola O principal desafio das politicas publicas voltadas para a educação indigena se refere a dificuldade de reconhecer a legıtımıdade dessas pedagogıas natıvas Dai a ımportâncıa da politıca de formação e contratação de professores indigenas consıderando que serão maıs propensos a utılizar as estrategias proprias de ensino e aprendizagem ou ao menos respeita las nas escolas indigenas 
Tomando ciência da demanda crescente entre os professores undigenas no Brasıl e precıso buscar meıos para viabılızar a sua formação contınuada em cursos de graduação e pos graduação especificos ou regulares em Instıtuições de Ensino Superıor (IES) publicas atraves de incentıvos funanceiros (repasse de verbas para as IESs e bolsas de estudo) A pesquisa em comunidades indıgenas sobre os processos de escolarızação deve ser incentivada (pedagogicamente e financeiramente) entre os professores indigenas objetıvando a reflexão contınua dos processos proprios de aprendızagem entre estes povos

Apesar dos avanços aunda se busca a consolıdação de uma politıca de educação escolar indıgena que sıga a Constıtuıção no seu pressuposto de assegurar as comunidades indıgenas a utılização de suas linguas maternas e processos proprios de aprendızagem Este trabalho exıgira um constante investımento publico no estudo das linguas e pedagogias natıvas e uma formação contınuada dos professores e profissionais destas escolas Finalmente e precıso consıderar a importâncıa da dıvulgação de informações atualızadas e corretas sobre as populações undıgenas do Brasıl como forma de combater o desconhecimento a intolerância e o preconceito em relação a esses povos Nesse sentıdo ressalta se a programação da TV/Escola sobre Povos Indıgenas no Brasıl como uma das poucas miciatıvas com esta finalıdade

Fol nesse contexto de transformações decorrentes da unserção da educação escolar nas aldeıas - horárıos, cargos assalarıados, formação de lıderanças letradas, novas expectatıvas de formação e de trabalho - que começaram a se desenvolver estudos acadêmicos sobre o tema Ilustratıvos do crescimento dessa produção acadêmıca são as revisões bıblıografıcas de Capacla (1995) e Grupıonı (2003) A prımeira analısou teses e livros a respeito da educação indıgena no Brasıl entre 1975 e 1995, enumerando 23 trabalhos Ja o inventanı elaborado por Grupıonı, a respeıto de dissertações e teses defendıdas no Brasıl sobre educação indıgena entre 1978 e 2002, apresentou 53 dissertações de mestrado e 21 teses de doutorado elaboradas em diferentes areas, especialmente Educação (37 trabalhos), Linguistıca (13) e Antropologı (12) Levantamento parcial de Lopes da Sılva (2001) estımou a produção bıblıográfıca brasıleıra sobre educação escolar ındıgena em torno de 200 títulos incluindo lıvros, artıgos teses e dissertações Tudo ındıca que esse número cresceu consıderavelmente a partır de então, inclusıve com maıor partıcıpação de autorıa indıgena, como e o caso do livro de Taukane (1999) 
No campo acadêmıco, consolıdam se os prımeuros gıupos de pesquisa sobre o tema É o caso do Grupo MARI de Educação Escolar Indígena, fundado no final dos anos 1980 por Lux Vidal, Aracy Lopes da Silva e uma equipe da pesquisadores da Unıversidade de São Paulo, com o objetıvo de desenvolver pesquısas sıstemátıcas e de prestar assessorıas sobre educação escolar ındıgena e sobre o ensıno da tematıca indigena As produções do MARI procuraram superar as lacunas mencionadas no inícıo deste artıgo (Lopes da Silva 2001) e alıar os avanços da etnologıa indigena sobre povos das terras baxxas da América do Sul e suas expenências de contato, a compreensão dos fenômenos decorrentes da escolarızação

A intensıfıcação das pesquisas de campo nos anos 1960 e 1970 levou ao reconhecimento de algumas questões fundamentais para compreender as sociedades indigenas sul americanas, de outra forma caracterızadas como fluıdas" ou "anômalas Os temas que têm destaque a partır de então são pruncıpalmente relacıonados à noção de pessoa, estudos sobre rutuais cosmologıas, noções de alterıdade e ıdentıdade, e sobre arte e manıfestações estetıcas Nas décadas de 1980 e 1990 também se untensıficam estudos sobre historia indígena atentos a presença indıgena e suas estrategıas de contato e estabelecumentos de alıanças com populações vizınhas, com o orgão tutor e com o estado em geral (Carneıro da Cunha, 1992, Souza Lıma, 1995 e Oliveira, 1999)

O acúmulo de pesquisas sobre povos de fala tupı, jê karıb, arwak e pano, permitem, nessa fase, a elaboração de tıpologıas, classıficações e comparações baseadas em aspectos sócio-culturaıs dos grupos indígenas, além daquelas baseadas no contato com a sociedade nacional desenvolvıdas na fase anterıor As coletâneas organızadas em 1993 por Descola e Taylor (La remontee de l Amazonie) e por Carneiro da Cunha e Viveiros de Castro (Amazônıa etnologia e historıa indıgena) demonstram a vitalidade dos estudos desenvolvidos nesse periodo No entanto, essas contribuıções não são ainda levadas a séno nos programas de escolas indígenas Tudo se passa como se essas refınadas análıses nada tivessem a ver com os processos educativos em curso nas aldeıas Refuro-me aqueles processos escolares e aos processos não escolares 
de transmissão de saberes, esses ultımos quase desconsıderados pela produção etnologıca brasıleıra

Nesse ponto chegamos a um aspecto comum que perpassa todos os perıodos analısados, traçando uma lınha de contınuıdade ao longo dos três momentos de ruptura o quase completo sulêncio a respeito de processos nativos de ensino e aprendizagem e o reconhecimento de sua importâncıa para a transmıssão de saberes natıvos ${ }^{6}$

Atribuo à experiência escolar que todos experımentamos a construção de um modelo impensado de "normalıdade" relacıonado a certa forma de ensıno e aprendızagem e a consequente oblıteração de quausquer outras formas que fujam a esse modelo Contınuamos a tratar como "normal" e "obvia" aquela defınıção clássıca de educação postulada por Durkheım "A ação exercıda pelas gerações adultas sobre as gerações que não se encontram ainda preparadas para a vida socıal" (1978 41) A essa característıca, que inevitavelmente enxerga o ensıno como uma relação hierárquica entre aqueles que sabem e aqueles que não sabem, os adultos e as crıanças, somam-se outras, tambem baseadas na experıência escolar a noção de que a aprendızagem se da por passos sucessivos e previsíveıs a idela de progresso na aquisıção de conhecimentos como uma sequência de etapas que devem ser seguıdas sem varıações, a importâncıa atrıbuída a escrıta para a transmissão de conhecımentos ou, no minımo, a oralıdade Desta forma, ha uma tendêncıa em qualıfıcar tudo que escapa dessas caracterıstıcas como "aprender fazendo" ou mera ımıtação, e ha uma grande dificuldade em reconhecer a legitumidade de outıas formas de transmissão de conhecumentos - o que acaba deslegitımando os proprios conhecimentos assim transmitidos

Estudos recentes sobre educação e, pruncipalmente, sobre crianças ındıgenas, têm demonstrado um camunho diverso e pleno de possıbılldades para a compreensão dos processos indıgenas de ensıno e aprendızagem As pesquisas pıoneıras desenvolvıdas no âmbito do grupo MARI por Nunes (1997) e Cohn (2000) com crianças Xavante e Kayapó, respectıvamente apontaram a importâncıa de se consıderar essas outras formas de vivenciar a infâncıa para a compreensão dessas sociedades ındigenas e seus processos de aprendızagem Desafio seguido por va- 
rios trabalhos desenvolvidos na ultuma década (Nunes, 2003, Olıveura, 2004, Álvares, 2005 Lecznıeskı, 2005, Codonho 2007, Lımulja, 2007 e Tassinarı, 2007) Podemos tambem obter informações sıgnıfıcatıvas nos trabalhos dedıcados aos ritos de inıcıação, as noções de pessoa, à sociologıa do conhecumento (Calavia Sáez et all 2003), que revelam aspectos importantes dos sistemas nativos de ensino e aprendızagem

Ainda que seja prematuro desenvolver conclusões a esse respeito, podemos finalizar esse artıgo com alguns aspectos recorrentes dessas pesquisas e que podem ser apontados como camınhos possiveıs para análıses sobre educação indıgena I) a aprendızagem por meıo de sonhos merece destaque, pois ha várıos exemplos etnograficos de sıtuações em que os neofitos são treınados para sonhar, sendo o sonho uma fonte legituma e umportante de saber, 2) tambem se destaca a aprendizagem por meı da embriaguez ou do uso de alucınogenos, onde há o reconhecimento de que certos saberes dependem de estados alterados de consciêncıa para serem compreendıdos, transmitıdos ou incorporados, 3) a ıdela de aprendızagem como "uncorporação" do conhecımento é também constante, e usada como justıfıcatıva para os ritos de inı cração que incluem reclusão, nos quais se nota um investmmento na produção dos corpos para a formação de pessoas étıcas e moraus, e um reconhecimento de que certos saberes só são adquurıdos em condições corporaıs específıcas, 4) ha que se atentar para os saberes que não são transmitıdos oralmente, mas que se apo-ıam em gestos e imagens - 0 sulêncio tambem e fonte de conhecimento, 5) destaca se, aunda, todo um universo de tecnicas e saberes que não são transmitıdos dos adultos as crianças, mas das crianças maıs velhas as maıs novas, sendo as crıanças elos importantes na manutenção do patrumônıo cultural undígena

Acredito que as escolas indígenas dificilmente poderão incluir alguns desses "processos próprıos de aprendızagem em seus currıculos, por se basearem em fontes de saber não legítımas para o conhecumento escolar No entanto, sera importante que essas novas pesquisas venham contribuir para a elaboração de propostas currıculares realmente atentas e respeitosas aos processos indigenas de aprendizagem, reconhecendo-os em sua alteridade, utılızando-os nas escolas quando isso for possível mas, ao menos, evitando que as rotınas escolares venham prcjudicar a sua realızação 


\section{Notas}

1 Este artıgo fol inicialmente elaborado para ser apresentado no Coloquio Senderos de la Antropologia historia e epistemologias organizado por Mechthlld Rutsch e Andres Medina no Instituto de Investıgaciones Antropologicas/UNAM em novembro de 2008 Agradeço a Esther Jean Langdon pelas sugestões que foram acrescidas no presente texto

2 De fato a atuação de Darcy Rıbeiro no campo da educação no Brasıl foı muıto alem da educação para indıgenas e de sua contrıbuıção para a formação de antropologos e indıgenistas Depois de sair do quadro do SPI em 1958 Darcy Riberro trabalhou no Centro Brasileiro de Pesquusas Educacionais e teve um importante papel na defınıção de polıtıcas publıcas educacıonaıs no pais A Leı de Diretrızes e Bases da Educação Nacional de 1996 tambem chamada Leı Darcy Rubeiro for elaborada sob sua coordenação enquanto Senador da Republıca

3 Art 215 O Estado garantıra a todos o pleno exercicıo dos direitos culturais e acesso as fontes da cultura nacıonal e apoıara e incentıvara a valorızação e a dıfusão das manıfestações culturais

$\S 1^{\circ} \quad \mathrm{O}$ estado protegera as manıfestações das culturas populares indıgenas e afro brasileiras e das de outros grupos participantes do processo civilızatorıo nacional Art 231 São reconhecıdos aos indıos sua organızação socıal costumes linguas cienças c tradıções e os dureitos ongınarıos sobre as terras que tiadicionalmente ocupam competindo a Unıão demarca las proteger e fazer respeitar todos os seus bens

4 Art $210 \S 2^{\circ}$ O enswo fundamental regular sera ministrado em lingua portuguesa assegurada as comunıdades ındıgenas tambem a utılızação de suas linguas maternas e processos proprios de aprendizagem

5 Dados publicados em INEP/MEC Estatıstıcas sobre educação escolar indigena no Brasıl 2007 a partir do censo escolar de 2005

6 Seria oportuno em outro momento refletır sobre os motivos que levaram a Antropologia nacional a praticamente silenciar sobre questões educativas enquanto cm outros contextos especialmente no cenario norte amencano a Antropologia fol ouvıda para a compreensão de problemas educacionass não apenas de povos nativos mas tambem da propria sociedade estadunidense

\section{Bibliografia}

ALVARES Myrıam Martıns Kıtoko Maxakalı a crıança ındıgena e os pro cessos de formação aprendızado e escolarızação Anthropologicas Recıfe n 15 p 49792005

ARNAUD Expedito O indio e a expansão nacıonal Belem CEJUP 1989 ASSIS Eneıda Escola indıgena uma frente ıdeologıca $>$ Dissertação (Mes trado em Ciêncıas Socıaıs) - Instıtuto de Cıêncıas Humanas Unıveısıda de de Brasilia Brasília 1981

BRAND Antonıo CASARO Adır URQUIZA Antonıo A crıança guaranı/ kaıowa e a questão da educação infantıl Serıe Estudos Campo Grande UCDB n 22 p 11232007

CAPACLA Marta O debate sobre a educação ındigena no Brasıl (1975 
1995) resenha de teses e lıvros Brasılıa MEC São Paulo MARI, USP 1995

CARNEIRO DA CUNHA Manuela (Org) Historia dos indios no Brastl São Paulo Companhia das Letras, Fapesp, SMC 1998

CALAVIA SAEZ Oscar CARID NAVEIRA, Miguel PEREZ GIL Laura O sa ber e estranho e amargo sociologia e mitologia do conhecimento entre os Yaminawa Campos - Revista de Antropologia Social Curitıba v 4 p 929 2003

CODONHO Camila Aprendendo entre pares a transmissão horızontal de sabe res entre as crianças indigenas Galıbı Marworno Dissertação (Mestrado em Antropologia Social) - Programa de Pos Graduação de Antropologia Social Centro de Fulosofia e Ciências Humanas Unıversıdade Federal de Santa Catarina Florianopolıs, 2007

COHN Clarıce $A$ crlança ındıgena a concepção xıkrın de infâncıa e apren dizado Dissertação (Mestrado em Antropologia Social) - Programa de Pos Graduação em Antropologıa Socıal Unıversıdade de São Paulo São Paulo 2000a

COHN Clarıce Crescendo como um Xıkrın uma analıse da infâncıa e do desenvolvimento infantil entre os Kayapo Xıkrin do Bacaja Revista de An tropologia v 43 n 2 p 195222 2000b

COHN Clance Escolas indıgenas no Maranhão um estudo sobre a experiêncıa dos professores indigenas In LOPES DA SILVA Aracy FERREIRA Manana Kawall Leal (Org ) Pratıcas pedagogıcas na escola indıgena São Paulo Global 200la p 107122

COHN Clarice Culturas em transformação os indios e a civiluzação São Paulo em Perspectiva v 15 n 2 p 36 42, 2001b

COHN Clance A experıêncıa da infâncıa e o aprendızado entre os Xıkrun In LOPES DA SILVA Aracy SILVA MACEDO Ana Vera Lopes da NU NES Ângela (Org) Crianças ındigenas ensaios antropologicos São Paulo Global 2002 p 117149

COHN Clarice Os processos de ensino e aprendizado e a escola undigena Cadernos de Educação Escolar Indigena Barra do Bugres MT Unemat, v 3 n 1 p 941112004

COHN Clarıce Educação escolar indıgena para uma dıscussão de cultura crıança e cıdadanıa atıva Perspectıva Florıanopolıs Ed da UFSC, 2005

COHN Clarıce Relações de diferença no Brastl Central os Mebengokre e seus outros Tese (Doutorado em Antropologia Social) - Programa de Pos Gra duação em Antropologıa Social Unıversıdade de São Paulo São Paulo 2006

CORREA Mariza A antropologia no Brasul (1960 1980) In MICELI Sergio (Org) Historia das ciêncıas socıaıs no Brasıl São Paulo Dumara Fapesp I995 $\vee 2$

DIAS Laercio Curso de formação treınamento e ofıcına para monitores e professores indigenas da reserva do Uaça In LOPES DA SILVA Aracy 
FERREIRA Marıana Kawall Leal (Org) Praticas pedagogicas na escola ind gena São Paulo Global 200I p 359378

DESCOLA Philippe TAYLOR Anne Christine (Org) La remontee de l Amazone anthropologie et historre des societes amazoniennes $L$ Hom me Parıs n 126128 p 13241993

DURKHEIM Emile Educação e socıologıa São Paulo Melhoramentos FNME 1978

FERNANDES Florestan Notas sobre a educação na sociedade Tupı Namba In Educação e soctedade no Brasıl São Paulo Domınus Edusp 1966 p 144201

FERREIRA Mariana Kawall Leal Da orıgem dos homens a conquista da escrita um estudo sobre povos indigenas e educação escolar no Brasıl Dıssertação (Mestrado em Antropologia Social) - Programa de Pos Gra duação em Antropologıa Socıal Unıversıdade de São Paulo, São Paulo 1992

FERREIRA Manana Kawall Leal A educação escolar ındıgena um dıagnos tıco critıco da situação no Brasıl In LOPES DA SILVA Aracy FERREIRA, Marıana Kawall Leal (Org) Antropologia historıa e educação a questão in dıgena e a escola São Paulo Global 200I p 71111

GALLOIS Domınıque Programa de Educação Wayãpı reıvındıcações indı genas versus modelos das escolas In LOPES DA SILVA Aracy FERREI RA Marıana Kawall Leal (Org) Pratıcas pedagogicas na escola indigena São Paulo Global 2001 p 2547

GARCIA Stella Marıs PALADINO Marıana (Org) Educacton escolar indige na investıgaciones antropologicas em Brasil y Argentına Buenos Aures Antropofagia 2007

GOMES Ana Marıa O processo de escolarızação entre os Xakrıaba explorando alternatıvas de analıse na antropologıa da educação Revista Brası letra de Educação v ll p 3163272006

GONÇALVES Marco Antonı Apresentação In NIMUENDAJU Curt Etno grafia e indigenismo Campınas Ed da Unicamp 1993 p 944

GRANDO Belenı Corpo e educação as relações interculturaıs nas pratıcas corporais Bororo em Merurı MT Tese (Doutorado em Clências Socıaıs) Centro de Fılosofıa e Ciêncıas Humanas Universıdade Federal de Santa Catarina Florianopolis 2004

GRUPIONI Lus Donısete (Org) Experiências e desafıos na formação de professores indigenas no Brasil Aberto Brasılia INEP v $20 \mathrm{n} 76 \mathrm{p} 13$ 182003

GRUPIONI Luis Donısete Formação de professores indigenas repensando tra jetorias Brasilıa MEC, 2006

GRUPIONI, Luıs Donısete A educação indıgena na academıa inventarıo co mentado de dıssertações e teses sobre educação escolar indigena no Brasıl (1978 2002) Aberto Brasilıa INEP/MEC v 20 n 76 p 1972382003

LECZNIESKI Lisıane Estranhos laços predação e cuidado entre os Kadıweu 
Tese (Doutorado em Antropologıa Socıal) - Centro de Fılosofia e Ciêncıas Humanas Universidade Federal de Santa Cataruna Florianopolıs 2005 LIMULJA Hanna Uma etnografia da escola indigena Fen No a luz da noção de corpo e das experiênctas das crianças Kaingang e Guaranı Dissertação (Mes trado em Antropologia Social) - Centro de Filosofia e Ciêncıas Humanas Unıversıdade Federal de Santa Catanna Florıanopolıs 2007

LOPES DA SILVA Aracy Uma antropologıa da educação no Brasıl? re flexões a partur da escolarızação indıgena In LOPES DA SILVA Aracy FERREIRA Marıana Kawall Leal (Org ) Antropologıa historia e educação a questão indıgena e a escola São Paulo Global 2001 p 2943

MINDLIN Betty A politica educacional indigena no periodo 19952002 al gumas reflexões Revista de Estudos e Pesquisas Brasilıa FUNAI v 1 n 2 p 1011402004

MARES DE SOUZA FILHO Carlos Frederico O direito envergonhado o di reito e os indios no Brasil In GRUPIONI Luis Donisete (Org ) Indios no Brastl São Paulo Secretarıa Munıcıpal de Cultura 1992

MELATTI Juhı Cezar A antropologia no Brasıl um roteiro Revista Brastletra de Informação Bibliografica em Ciências Socıals Rıo de Janeiro n 17 p 352 1984

MELATTI Julı Cezar Dialogos Jê a pesquisa Kraho e o projeto Harvard Museu Nacional Mana v 8 n 1 p 181 193, 2002

MELATTI Juho MELATTl Delvair A crıança Marubo educação e cuıdados Revista Brasiletra de Estudos Pedagogicos Brasilua v 62 n 143 p 291301 jan /mar 1979

METRAUX Alfred, DREYFUS ROCHE, Simone La naissance et la premere enfance chez les undiens Cayapo du Xungu In Miscellanea Paul Rl vet Mexico D UNAM 1958 v 2 p 363378

MONTE Nietta Escolas da floresta entre o passado oral e o presente letrado Ruo de Janeuro Multıletra, 1996

NASCIMENTO Adır Escola indigena palco das diferenças Campo Grande UCDB 2004

NUNES Ângela $A$ soctedade das crianças $A$ uwê Xavante por uma antropologıa da criança Dıssertação (Mestrado em Antropologia Social) - Programa de Pos Graduação em Antropologia Social Unıversıdade de São Paulo, São Paulo, 1997

NUNES Ângela Brıncando de ser crıança contrıbuções da etnologıa indıgena brasileura a antropologia da infância Tese (Doutorado em Antropologia da Educação) - Instıtuto Superıor das Ciências do Trabalho e da Empresa Lisboa 2003

OLIVEIRA Melıssa Kırıngue $\iota$ Kuery Guaranı infâncıa educação e relıgıão entre os Guaranı de $M$ Bıguaçu Dissertação (Mestrado em Antropologıa Social) - Programa de Pos Graduação em Antropologia Social Centro de Fılosofıa e Ciêncıas Humanas Unıversıdade Federal de Santa Catarına Florianopolıs 2004 
OLIVEIRA, João Pacheco Ensatos em antropologia historica Rıo de Janelro Ed da UFRJ 1999

PALADINO Mariana Estudar e expertmentar na cidade trajetorias socials es colarızação e experıência urbana entre jovens indıgenas Tese (Doutorado em Antropologıa Socıal) - Programa de Pos Graduação em Antropologıa Socıal Museu Nacional Universıdade Federal do Rıo de Janeiro Rıo de Janeiro 2006

RIBEIRO Darcy Os indios e a civtlızação a integração das populações indige nas no Brasıl moderno São Paulo Companhı das Letras 1996 Orıgınal de 1970

SANTOS Silvo Coelho dos Educação e socıedades tribaıs Porto Alegre Movı mento 1975

SANTOS Sílvio Coelho dos Indios e brancos no Sul do Brasil Porto Alegre Movimento, Brasilia MINC Pro Memoria INL 1973

SANTOS Silvio Coelho dos Os indigenas e a Constıtumnte Porto Alegre Movı mento Florianopolıs Ed da UFSC 1989

SANTOS Silvio Coelho dos (Org) Memorıa da antropologıa no Sul do Brasil Florianopolis Ed da UFSC ABA 2006

SANTOS Sílvıo Coelho dos Formação unıversıtarıa e lıderanças ındıgenas na Regıão Sul In Ensatos oportunos Florianopolis Academia Bra sileura de Letras Nova Letra 2007 p 129 I35

SANTOS Sılvio Coelho dos TASSINARI Antonella WEBER Catıa Revı sando a LDB e o Plano Nacıonal de Educação In AUDIÊNCIA PUBLICA DA COMISSÃO DE EDUCAÇÃO DA ASSEMBLEIA LEGISLATIVA 2007 Florıanopolıs 2007 Comunıcação apresentada Manuscrito

SCHADEN Egon Educação e magıa nas cerımônıas de ınıcıação Revista Brastletra de Estudos Pedagogicos Rio de Janeiro v 3 n 8 p 27I 274 fev 1945

SCHADEN Egon Educação indıgena Problemas Brasıleıros v 14 n 152 p 23321976

SOUZA LIMA Antonı Carlos de Um grande cerco de paz poder tutelar indıa nidade e formação do Estado no Brasıl Petropolıs RJ Vozes 1995

SOUZA LIMA Antonı Carlos de Educacion superıor para indigenas en el Brasil mas alla del sistema de cupos In GARCIA Stella Maris PALADI NO, Mariana (Org) Educacion escolar indigena investigaciones antropo logicas en Brasıl y Argentina Buenos Aures Antropofagıa 2007 p 257 277

TASSINARI Antonella Os povos indıgenas do Oıapoque produção de diferen ças em contexto interetnico e de politıcas publıcas Florıanopolıs PPGAS UFSC 1999 (Coleção Antropologıa em Prımeıra Mão 39)

TASSINARI Antonella Da cıvilızação a tradıção os projetos de escola entre os indıos do Uaça LOPES DA SILVA Aracy FERREIRA Marıana Kawall Leal (Org) Antropologıa hıstona e educação a questão indigena e a escola São Paulo Global 2001a p 157195 
TASSINARI Antonella Escola indigena novos horizontes teoricos novas fronteiras de educação FERREIRA Marıana Kawall Leal (Org ) Antropo logia historia e educação a questão indigena e a escola São Paulo Global 2001b p 4470

TASSINARI Antonella Concepções indigenas de infâncıa no Brasıl Tellus Campo Grande UCDB ₹ 7 n 13 p 1125 out 2007

TAUKANE Darlene A historia da educação escolar entre os Kurâ Bakaırı Culaba Edição da Autora 1999

TINOCO Silva Ekolya et karetajar maltre de lecole maître de lecriture 1 incorporatıon de l ecriture et de l ecole par les amerındıens Wayãpı de 1 Amaparı (Bresil) et de l Oyapock (Guyane françaıse) Tese (Doutorado em Antropologia) - Ecole des Hautes Etudes en Sciences Socıales Parıs 2006

WILLEMS Emulıo Posição social e educação dos imaturos entre povos natu rais Revista do Arquivo Municipal São Paulo v 5 n 49 p 5341938 VIVEIROS DE CASTRO Eduardo CARNEIRO DA CUNHA Manuela (Org) Amazônıa hıstona e etnologıa São Paulo FAPESP NHII 1993 